\title{
Gender Differences in Social Support Among Older Adults ${ }^{1}$
}

\author{
Neal Krause ${ }^{2}$ and Verna Keith \\ University of Michigan, Ann Arbor
}

The purpose of this study was to determine whether exposure to life stress can help explain gender differences in the use of social support. Findings from a longitudinal study suggest that as the number of stressful life events increase, elderly men and women are equally likely to become more involved in their social network, while gender differences emerge only in response to chronic financial strain. Further analysis indicates that elderly women are more likely than elderly men to report that the support they received increased their feelings of personal control.

Research on social support has continued to be a dominant force in the gerontological literature during the past decade (see Antonucci, 1985a, for a review of this research). The bulk of this work, however, has focused primarily on the impact of social support on health and psychological well-being, while considerably less attention has been devoted to those factors that influence the utilization of social support networks in the first place (Antonucci, 1985a). Stated simply, extensive research has not been devoted to social support as a dependent variable (Levine \& Perkins, 1987; Dunkel-Schetter, Folkman, \& Lazarus, 1987).

Existing studies on the etiology of social support have been concerned mostly with the demographic correlates of supportive social relations. Here researchers have expressed particular interest in gender differences in the propensity to seek and receive assistance from others (see the entire Decem-

'This study was funded by Grant R23 AG/MH 04747 from the National Institute on Aging and a grant from the Hoog Foundation for Mental Health (Austin, Texas).

${ }^{2}$ To whom correspondence should be addressed at Health Gerontology Program, School of Public Health, the University of Michigan, 1420 Washington Heights, Ann Arbor, Michigan 48109-2029. 
ber 1987 issue of Sex Roles for a review of this research). These studies tend to suggest that elderly women maintain wider and more well-developed social networks than their male counterparts (see Antonucci, 1985b, for a review of this literature). Indeed, over the entire life course women appear involved in larger and more diverse networks than men (Campbell, 1980; Veroff, Douvan, \& Kulka, 1981).

Although this descriptive information provides a vitally important first step in developing the knowledge base, demographic variables such as gender fail to provide a sense of the dynamics involved in the social support process. Clearly, psychosocial factors must link gender with social support utilization, and it is imperative that these intervening mechanisms are identified and measured explicitly. Focusing on the benefits derived from encounters with others may provide a useful point of departure for understanding gender differences in the social support process. Although little is known about the specific benefits that women may derive from greater involvement with significant others, a careful examination of recent developments in the literature on stress and social support may provide some useful preliminary insights.

\section{Stress and Social Support}

There is now considerable evidence that exposure to life stress increases the use of social support networks (see Alloway \& Bebbington, 1987, for a discussion of this crisis-support hypothesis). In order to understand how social support may benefit individuals who are exposed to stress, it is important to first examine how stressful events affect individuals.

According to Caplan (1981), stressful life events affect people primarily by eroding their sense of mastery or personal control. Pearlin and his associates capture the essence of this perspective when they note that stress "can confront people with dogged evidence of their own failure - or lack of success - and with inescapable proof of their inability to alter the unwanted circumstances in their lives" (Pearlin, Menaghan, Lieberman, \& Mullan, 1981, p. 340).

If stress affects individuals by diminishing their sense of personal control, then social support may help individuals cope with life crises by bolstering this important personal resource. Caplan (1981) provides a convincing theoretical rationale for linking social support with feelings of personal control. He argues that an effective support group helps replenish feelings of control by providing the stressed individual with concrete aid in dealing with his or her problem: significant others help evaluate the situation, formulate a plan of action, assist in the implementation of this plan, and provide feed- 
back and guidance while the plan is being executed. Given this assistance, the stressed person comes to feel the problem situation can be controlled.

A careful review of the literature suggests that while social support may generally tend to enhance feelings of personal control, there are at least two reasons why women may be more likely than men to take advantage of these benefits. The first reason has to do with the fact that women are more likely to utilize supportive networks in the first place, while the second focuses on gender differences in the nature or quality of these supportive encounters.

Due in part to differences in the socialization process, some investigators suspect that women are more likely than men to seek the assistance of significant others in times of high stress (Kessler, McLeod, \& Wethington, 1985; DeFares, Brandes, Nass, \& van der Ploeg, 1985). More specifically, researchers argue that during childhood, boys are taught to repress emotions and to act autonomously, thereby limiting their ability to ask for and receive support. In contrast, girls are taught to express emotion, which has been hypothesized to encourage the development of mutually supportive social relations (see Block, 1979, for a review of this literature). These early socialization experiences appear to affect the social relationships of men and women throughout the life course. At every age, women report more extensive and emotionally intimate relationships than men (see Antonucci, 1985b, for a review of this research).

Although there may be gender differences in the amount of social contact made during stressful periods, the literature further suggests that women may be especially likely to reap the control-enhancing rewards described by Caplan (1981). Research by Fasteau (1974) indicates that men are less likely than women to share half-formulated plans with friends. This finding is supported by literature showing that females self-disclose more often than males (see Butler, Giordano, \& Neren, 1985, for a review of these studies). It appears as though it would be difficult to utilize one's support to formulate effective plans for coping with stress without some degree of self-disclosure. Thus, support should lead to greater feelings of control among women than among men.

The purpose of this study is to determine whether these potentially important gender differences extend into later life. In the process, an effort will be made to extend the theoretical process described above in two important ways. These additional theoretical specifications are based on the premise that life stress and social support are multidimensional phenomena. Consequently, an attempt will be made to determine whether focusing on specific types or dimensions of stress will enhance the predictive power of the model. Similarly, specific types or dimensions of social support will also be examined in order to assess whether they impact differentially on feelings of perceived control. Justification for these theoretical extensions is presented below. 


\section{Examining Specific Types of Stressors}

Extensive reviews of the life events literature suggest that stressors do not exert similar effects, and that individuals are most likely to be influenced by those major or severe events that they cannot control (see Thoits, 1983, for a review of this research). If stress affects support utilization and if gender differences arise in this process, then perhaps these differences will be most evident when we focus on those events that are severe and that older adults are unable to control. In effect, this literature suggests that gender differences in social support utilization may vary depending upon the type of stressor under consideration.

Pearlin provides a useful framework for distinguishing between major stressors and those events that are less severe (Pearlin et al., 1981). According to his view, the most noxious types of stressors are chronic life strains, which are thought to be continuous and an ongoing. In contrast, he refers to less debilitating stressors as stressful life events, which are transitory and of relatively short duration.

Research suggests that financial problems among older adults are likely to be persistent, and that the effects of these financial difficulties may be especially evident among elderly women. A study by Krause (1987), for example, showed that self-reported financial strain among elderly men and women remained highly stable over an 18-month period, suggesting that this form of stress may constitute a long-term threat. Perhaps more important, personal economic problems may create long-term difficulties because they can trigger a series of secondary stressors, such as housing problems, lower standards of nutrition, and even shorter life expectancies (Varghese \& Medinger, 1979; Pearlin et al., 1981).

Although chronic financial strain appears an ongoing problem for older adults in general, there is some evidence that elderly women are more likely than older men to experience this type of difficulty. For example, research by Holden (1988) indicates that approximately $52 \%$ of all poor elderly persons are women who either live alone or who reside with nonrelatives. She refers to this alarming pattern as the "feminization of poverty at older ages."

As the literature reviewed earlier suggests, the most detrimental stressors are those events that individuals feel they are unable to control. There are at least two factors that may limit the ability of elderly women to exercise control over their financial difficulties. First, as Morgan (1984) observes, elderly women have limited opportunities to improve their economic situation through paid employment. In contrast, older men can avoid serious financial problems by returning to either full- or part-time employment. In fact, as Burkhauser, Holden, \& Feaster (1988) report in a recent article, approximately $20 \%$ of older men elect to return to work following retirement. 
Elderly women may also feel as though they are unable to exercise control over their economic problems because of cohort-related inexperience with handling money (Hyman, 1983). A number of researchers suspect that elderly women are frequently involved in marriages where the husband maintains tight control over family financial decisions as well as financial information. As a result, elderly married women may have limited opportunities to participate in developing a response to a financial crisis should one arise. The situation may be even more difficult for widows because they may find themselves forced to deal with problems in an area where they have had limited practical experience (see Morgan, 1986, for a detailed discussion of this problem).

\section{Examining Specific Types of Social Support}

According to the theoretical framework presented above, social support functions primarily by bolstering feelings of personal control in older adults (especially in elderly women). As it currently stands, however, this discussion is cast solely in terms of support received by elders from the members of their social networks. In addition to evaluating the effects of received support empirically, an effort will be made to determine whether other types or dimensions of support also perform this important function. More specifically, these additional analyses will assess whether providing support to others also enhances feelings of control among elders and whether gender differences emerge in this relationship.

As discussed earlier, women have larger social networks and receive more support than men across the life course. However, a number of investigators have noted that support is often provided with the expectation that others will reciprocate in the future should the need arise (see Wortman and Dunkel-Schetter, 1987, for a review of this research). As Lee (1985) and others suggest, this norm of reciprocity takes on special importance in later life as older adults strive to avoid becoming overly dependent upon others.

For some time, mental health professionals have been aware that individuals who provide support to others often benefit themselves from the help-giving role (Reissman, 1965). In fact, this "helper principle" has formed the basis of many self-help groups, such as Alcoholics Anonymous. There are at least three reasons why providing support to others is beneficial. First, giving to others bolsters the self-esteem of the help providers because they feel as through they are doing something for someone in need. Moreover, by helping others, the attention of the support provider may be diverted from his/her own problems or concerns. Finally, and most important for the purposes of this study, giving help to others and observing that this assistance 
can improve the situation of a needy significant other may lead the help provider to see that his or her own problems may be influenced similarly, thereby increasing their feelings of control.

\section{Hypotheses}

The literature reviewed in the previous sections suggests that in times of high stress, elderly women may be more inclined than elderly men to seek support from significant others. However, it was also noted that the proposed gender differences would be especially evident when events are severe and women believe they have little control over them. This research further indicates that women may enjoy greater benefits from supportive interactions with others because these contacts are more likely to enhance feelings of personal control among elderly women.

The goal of the present study is to evaluate this argument empirically. Three specific hypotheses will be tested. First, it is predicted that significant gender differences will emerge when the impact of a global stressful life events measure on social support is examined. However, it is further hypothesized that even greater differences will be observed when the impact of chronic financial strain on social support is assessed. Finally, it is predicted that elderly women will be more likely than elderly men to report that the support they have received and given has increased their feelings of personal control.

It is hoped that by moving beyond the analysis of demographic correlates of social network use, the present study will begin to provide valuable insights into the dynamics of the social support process. That the analyses that follow are based on longitudinal data should serve to heighten the sense dynamics involved in this process further.

\section{METHODS}

\section{Sample}

The participants in this study were selected at random in a survey of community-dwelling persons 65 years of age and older who lived in Galverston, Texas, in 1984. A replicated sample approach (without supplementation) was used based upon the R. L. Polk city directly (see Kish, 1965, for a detailed discussion of replicate sampling). One eligible person per household was selected with the Kish grid selection method (Kish, 1965). All interviews were conducted face-to-face in the homes of the study participants (see Krause, 1986, for a detailed discussion of this field work). 
Completed interviews were obtained from 351 older adults, representing $78 \%$ of the eligible persons contacted. Sixty-six percent of the sample were women and $34 \%$ were men. The average age of the study participants was 73.4 years $(S D=6.2$ years). Sixty-four percent of the respondents were white, $27 \%$ were black, $7 \%$ were Hispanic, and $1 \%$ were of other races. Forty-one percent of the older adults in this study were married at the time of the baseline interview, $40 \%$ were widowed, and $19 \%$ were either divorced, separated, or never married. Finally, the respondents had an average of 9.9 years of completed education ( $S D=4.2$ years).

Approximately a year and a half later, 265 of the original 351 study participants $(75.5 \%)$ were located and successfully interviewed. The mean interval between the baseline (T1) and the follow-up (T2) interviews was 18.7 months ( $S D=1.9$ months). Of the 86 respondents who were lost to followup, 32 refused to be interviewed, 23 had died, 19 could not be located, 8 had moved out of state, and 4 had been institutionalized.

Subjects attrition presents a serious threat to panel studies if it occurs in a nonrandom fashion. For example, a disproportionate loss of subjects with low social support would make it difficult to assess the impact of stress on support through time. A discriminant analysis was performed in order to determine whether nonrandom subject loss occurred in this study. The results from this analysis suggest that the baseline indicators of the constructs used in this study failed to significantly differentiate those subjects who remained in the study and those who were lost to follow-up (a detailed description of these measures is presented below). A table containing the results of these analyses is available from the author upon request.

\section{Measures}

Social Support. Identical measures of social support were obtained at both the baseline and follow-up interviews. Social support was measured with a modified version of the Inventory of Socially Supportive Behaviors (Barrera, Sandler, \& Ramsay, 1981; see Krause, 1986, for a detailed description of this measure). The revised 41 -item scale assesses four types of social support: emotional support, tangible help, informational assistance, and support provided to others. Each dimension of support is treated as a separate construct in the analyses provided below. Respondents were asked at the baseline interview to report how much social support they had received or provided in the previous year. At the follow-up contact they were asked for information on the support they had received or provided since the previous interview. A high score on any of these measures reflects greater social support. 
Emotional support is based on the personal qualities or behavior of a support person, including empathy, caring, love, and trust. Preliminary data analysis revealed that internal consistency reliability estimate for this 11-item opposite at the baseline interview was $\alpha=.827$.

Tangible assistance reflects instrumental behavior that helps a respondent directly. This direct aid may involve a financial contribution, help with transportation, or assistance with household chores. Based on the T1 data, the reliability of this 9 -item subscale was $\alpha=.665$.

Informational aid helps stressed persons by providing them with knowledge or insights that they can use to resolve a stressful situation. The internal consistency of this 8-item composite at T1 was $\alpha=.814$.

Finally, the subscable assessing support provided to others was designed to determine how much information, tangible, and emotional support the study participant provided to members of his or her social network. On the basis of the T1 data, the reliability of this 13-item composite was $\alpha=.812$.

Stressful Life Events. Stressful life events were measured with a 77-item checklist that was developed especially for this study. Age-relevant stressors were taken from existing scales and grouped into the following life areas: events involving the respondent's children, spouse, other relatives, friends, neighborhood, finances, and crime. In addition, each of these sections ended with an open-ended item that asked respondents to report whether anything else has happened in that area. For example, after the respondents were presented with the events pertaining to their children, they were asked whether any other stressors had occurred that involved their children.

A global index of self-rated undesirable life events was created by simply summing the number of events that the respondents had experienced between the baseline and follow-up interviews. Although information was available on life events that had occurred prior to the baseline interview, only the T2 measure was used in this study because the goal of the analyses was to examine the impact of stress on changes in social support (i.e., the effects of stress on $\mathrm{T} 2$ support after the effects of $\mathrm{T} 1$ support have been controlled statistically). The use of the T1 stress measure would have led to an entirely different and less meaningful hypothesis because we would expect the greatest impact of the baseline measure of stress to be exerted on the baseline measures of support, thereby making it difficult to show how stress affects changes in support through time.

The study participants reported that they had experienced an average of 2.2 undesirable life events $(S D=2.0)$ between the baseline and follow-up interviews. A high score on this index reflects exposure to a greater number of stressful life events.

Chronic Financial Strain. Chronic financial strain was measured with a brief four-item composite taken from the work of Pearlin et al. (1981). 
The items in this scale assess whether the respondents feel as though they have enough money for food, medical care, clothing, and leisure activities. The responses to these items were coded in the following manner: never (1), once in a while (2), fairly often (3), and very often (4) (scoring in parentheses). Preliminary analyses were performed in order to determine how often the older adults in this sample experienced financial difficulties. The study participants were considered to have financial problems if they received a score of 2 or greater on an item. The preliminary analyses revealed that $36 \%$ of the respondents scored 2 or higher on one or more of the financial strain items. Moreover, the analyses further indicated that $9 \%$ of the older adults in this sample scored 2 or higher on every one of the four items contained in the scale.

Consistent with the logic provided above, only the T2 measures of financial strain will be used in the analyses provided below. The internal consistency reliability estimate for this index at the follow-up interview was $\alpha=.871$. A high score on this measure indicates greater financial difficulty.

Personal Control. As discussed above, research indicates that social support functions primarily by making individuals feel as though they are in control of the events in their lives (Caplan, 1981). Due in part to socialization differences, it was predicted that elderly women would be more likely than elderly men to feel as though the support from others increased their feelings of personal control.

Most of the existing research on feelings of personal control has relied exclusively on global scales that assess generalized control beliefs, such as the Rotter Internal-External Locus of Control Scale (Rotter, 1966). Recently, however, a number of investigators have begun to question the usefulness of such global indices, arguing instead that researchers should examine feelings of control in specific life domains, such as health and finances (see Rodin, Timko, \& Harris, 1985, for a discussion of this issue). According to this view, individuals derive somewhat independent assessments of their ability to control different areas in their lives, and it is possible to feel a high degree of control in one domain but not in another. Embedded in this position is the belief that measure of control should be tailored specifically to the research question at hand.

Based on this rationale, a decision was made not to rely on a global measure of control in this report. Instead, a measure was devised especially for this study that specifically links feelings of personal control with the support that has been provided to the study participant. Immediately following the administration of the social support scales described above, the respondents were presented with the following items at both T1 and T2: "For the past few minutes we've talked about things that others have done for you as well as help that you have given to others. When you think back over 
all the help that has been provided [in the past year (T1)/since the last interview (T2)], would you say it makes you feel as if you had no control, some control, or a lot of control over the events and changes in your life?" By using this type of measure it was possible to conduct a more precise test of the hypothesis that support bolsters feelings of control and that gender differences exist in this linkage. A high score on this indicator reflects greater feelings of control.

Social Desirability. Research findings suggest that response bias is a pervasive problem in survey research (Carr \& Krause, 1978), and there is some evidence indicating that it may be a greater problem with older respondents than with younger study participants (Bradburn \& Sudman, 1978). Even though serious data analytic problems may be created by response bias, gerontologists have rarely attempted to control for this type of systematic error in surveys of older adults (Bengtson, Reedy, \& Gordon, 1985).

The effects of social desirability response bias were examined in this study by presenting respondents with a shortened 9-item version of the Marlowe-Crowne Social Desirability Scale (Crowne \& Marlowe, 1964). An exploratory factor analysis of these items produced two theoretically meaningful factors that were comprised of the positive and negatively keyed items respectively. The negatively keyed items were used in this report to create a brief 4-item composite that assesses the tendency to disclaim disapproved qualities (Henderson, Bryne, \& Duncan-Jones, 1981). A high score on this scale indicates a greater need for social approval (i.e., greater response bias).

Demographic Measures. The relationships among social support, stress, and feelings of control were examined after the effects of age, sex ( 1 = males; $0=$ females $)$, marital status ( $1=$ married; $0=$ otherwise $)$, and education had been removed statistically. Education was scored as a continuous measure reflecting the total number of years of completed educational attainment.

\section{Data Analysis Issues}

The first hypothesis to be tested in this study states that there are gender differences in the impact of stressful life events on social support. If the effects of one independent variable (life stress) on a dependent variable (social support) are contingent upon the level of a second independent variable (gender), then a statistical interaction effect is present.

Tests for statistical interaction effects were performed with ordinary least squares multiple regression analysis that contained a multiplicative term. More specifically, the regression equation for this study took the following form:

$\mathrm{SS}_{2}=a+b_{1} \mathrm{SS}_{1}+b_{2} \mathrm{SE}_{2}+b_{3} \mathrm{SEX}+b_{4}(\mathrm{SEX} \times \mathrm{SE})+\Sigma c_{i} z_{i}+e(1)$ 
In this equation, social support at the follow-up interview $\left(\mathrm{SS}_{2}\right)$ is predicted by baseline social support scores $\left(\mathrm{SS}_{1}\right)$, stressful events at $\mathrm{T} 2\left(\mathrm{SE}_{2}\right)$, gender (SEX), a multiplicative term representing the interaction effect of gender and stressful events (SEX $\times$ SE), and the demographic variables $\left(z_{i}\right)$. The $b_{i}$ and $c_{i}$ in Eq. (1) denote unstandardized regression coefficients, $a$ is the intercept term, and $e$ stands for the residual.

It should be emphasized that Eq. (1) is a lagged model. This means that the coefficients in this equation may be interpreted as the effects of the independent variables on changes in social support $\left(\mathrm{SS}_{2}-\mathrm{SS}_{1}\right)$.

Equation (1) is estimated in a hierarchical fashion where the baseline measure of support, stress, sex, and the demographic measures are entered in the first step while the multiplicative term is added in the second step. If the multiplicative term is significant, the effects of stress (SE) cannot be interpreted independently of the multiplicative term (SES $\times \mathrm{SE})$. As Stolzenberg (1980) demonstrates, the effects of $\mathrm{SE}_{2}$ on $\mathrm{SS}_{2}$ are given by

$$
\partial \mathrm{SS}_{2} / \partial \mathrm{SE}_{2}=b_{2}+b_{4}(\mathrm{SEX})
$$

As shown in Eq. (2), the impact of stress depends on the gender of the study participant. Since gender is a binary variable that can only take on the values of 0 and 1 , the impact of stress for men is

$$
\partial \mathrm{SS}_{2} / \partial \mathrm{SE}_{2}=b_{2}+b_{4}(1)
$$

Similarly, the effect of stress on support for women is given by

$$
\partial \mathrm{SS}_{2} / \partial \mathrm{SE}_{2}=b_{2}+b_{4}(0)=b_{2}
$$

The remaining hypotheses in this study also specify statistical interaction effects. Accordingly, the hierarchical regression procedure described in this section will also be used to test for these interaction effects.

\section{RESULTS}

The first goal of this study is to test for gender differences in the use of social support in response to life stress. It was hypothesized that gender differences may arise in response to both stressful life events as well as chronic financial strain. Table I contains the findings from the first step in the hierarchical regression analyses that were designed to evaluate these hypotheses. As reflected in Table I, four separate regression analyses were performed one for each of the four dimensions of social support.

Several interesting findings emerge from Table I with respect to the additive effects of stress and gender. The data suggest that in general, as the number of stressful life events increase, older adults tends to show greater involvement in their social networks at the follow-up interview. More spe- 
Table I. Addictive Effects of Global Life Events and Chronic Financial Strain on Social Support (T2) $(N=243)$

\begin{tabular}{lcccc}
\hline & \multicolumn{4}{c}{ Dependent variables } \\
\cline { 2 - 5 } Independent variables & $\begin{array}{c}\text { Informational } \\
\text { support (T2) }\end{array}$ & $\begin{array}{c}\text { Tangible } \\
\text { support (T2) }\end{array}$ & $\begin{array}{c}\text { Emotional } \\
\text { support (T2) }\end{array}$ & $\begin{array}{c}\text { Support to } \\
\text { others (T2) }\end{array}$ \\
\hline Age & $-.032^{a}$ & -.020 & -.068 & -.022 \\
Sex & $(-.021)^{b}$ & $(-.015)$ & $(-.087)$ & $(-.027)$ \\
Marital status & -.072 & $.184^{d}$ & -.055 & -.047 \\
Education & $(-.623)$ & $(-1.837)$ & $(-.934)$ & $(-.763)$ \\
& .071 & -.033 & -.054 & -.013 \\
Social desirability & $(.589)$ & $(-.317)$ & $(-.878)$ & $(-.203)$ \\
Stressful events & .011 & -.086 & -.042 & .002 \\
& $(.011)$ & $(-.096)$ & $(-.079)$ & $(.004)$ \\
Financial strain & -.077 & -.099 & -.054 & -.008 \\
& $(-.279)$ & $(-.415)$ & $(-.384)$ & $(-.057)$ \\
Informational support (T1) & $.279^{e}$ & $.183^{e}$ & $.216^{e}$ & $.215^{e}$ \\
Tangible support (T1) & $(.567)$ & $(.431)$ & $(.861)$ & $(.820)$ \\
& .077 & -.032 & -.018 & .054 \\
Emotional support (T1) & $(.107)$ & $(-.051)$ & $(-.048)$ & $(.140)$ \\
Support to others (T1) & $.271^{e}$ & & & \\
Multiple $R^{2}$ & $(.276)$ & & & \\
\hline
\end{tabular}

${ }^{a}$ Standardized coefficient.

${ }^{b}$ Unstandardized (metric) coefficient.

${ }^{c} p<.05$.

$d_{p}<.01$.

${ }^{e} p<.001$.

cifically, the findings indicate that as exposure to global stressful events increases, both elderly men and women report an increase in the amount of informational (beta $=.229 ; p<.001$ ), tangible (beta $=.183 ; p<.001$ ), and emotional support (beta $=.216 ; p<.001$ ) they have received at $\mathrm{T} 2$. In addition, elderly men and women report that they provided more support to others at the follow-up interview as the number of these life stressors in their lives increase (beta $=.215 ; p<.001$ ).

The data in Table I further reveal that there were no significant effects of chronic financial strain on any of the follow-up measures of social support. This suggests that as persistent financial difficulties increase, older adults do not provide or receive an increased amount of social support.

Finally, the data in Table I indicate that there is a significant relationship between gender and changes in tangible support. More specifically, the results suggest that irrespective of the amount of stress present, elderly women 
tend to receive more tangible assistance through time than elderly men (beta $=-.184 ; p<.01$ ).

Although the additive effects of stress and gender on support are of some interest, the goal of the study is to determine whether there is an interaction effect between gender and stress on changes in the amount of support that old adults receive and provide. As discussed above, this information may be obtained when a multiplicative term representing the product of these indicators is added to the regression equation in the second step of the hierarchical analysis. The results of these analyses are presented in Table II.

Three points should be emphasized about the data presented in Table II. First, the estimates were derived after controls had been established for the effects of age, marital status, education, social desirability, the baseline measures of support, as well as the additive effects of stress and gender. In addition, only unstandardized parameters are presented in Table II in order to avoid confounding gender differences in the effects of stress on support with differences in the item variances across groups. Finally, the estimates presented in Table II were computed with the formula depicted in Eq. (2). Thus, the estimates represent the impact of stress on changes in social support separately for men and women.

Two overall trends emerge from the data presented in Table II. First, in no instance is the impact of the global stress measure on changes in social support greater for elderly women than for elderly men. When combined with the findings from Table I, these analyses suggest that elderly women do not have a greater propensity than older men to seek or provide increased support in response to global life events. However, as shown in Table I, global stress leads to greater changes in support for both men and women.

Table II. Gender Differences in the Impact of Global Life Events and Chronic Financial Strain on Social Support $(\mathrm{T} 2)^{\alpha}(N=243)$

\begin{tabular}{lcccc}
\hline & \multicolumn{4}{c}{ Dependent variables } \\
\cline { 2 - 5 } & $\begin{array}{c}\text { Informational } \\
\text { support (T2) }\end{array}$ & $\begin{array}{c}\text { Tangible } \\
\text { support (T2) }\end{array}$ & $\begin{array}{c}\text { Emotional } \\
\text { support (T2) }\end{array}$ & $\begin{array}{c}\text { Support to } \\
\text { others (T2) }\end{array}$ \\
\hline $\begin{array}{l}\text { Effects of global stressful } \\
\text { life events for } \\
\text { Men }\end{array}$ & & & & \\
$\quad \begin{array}{l}\text { Women } \\
\text { Effects of chronic financial }\end{array}$ & $.148^{b}$ & .292 & .194 & .672 \\
strain for & .668 & .465 & 1.025 & .857 \\
$\quad$ Men & & & & \\
Women & -.045 & .078 & .277 & .194 \\
\hline
\end{tabular}

${ }^{a}$ Estimates were derived after controlling for the effects of age, marital status, education, social desirability, the baseline measures of support, as well as the additive effects of stress and gender.

${ }^{b}$ Unstandardized (metric) coefficient.

${ }^{c}$ Difference between coefficient for men and women is significant at the .05 level. 
Returning to Table II, a different picture emerges with respect to chronic financial strain. The data suggest that elderly women receive significantly more tangible support $(b=.412)$ at the follow-up interview in response to chronic financial strain than elderly men $(b=.078)$. Similarly, when levels of financial strain are high, elderly women report receiving more emotional assistance $(b=.832)$ at T2 than men $(b=.277)$. Finally, in times of financial difficulty, elderly women indicate that they provide more support to others $(b=.785)$ at $\mathrm{T} 2$ than do elderly men $(.194)$. Informational support represents the only dimension of support not influenced by gender differences in response to financial strain.

A second major purpose of this study was to determine whether elderly women receive certain benefits from supportive social relations not enjoyed by older men. More specifically, it was predicted that women are more likely than men to report that the support they received increased their feelings of personal control. Consistent with the data analytic procedures used in the previous analyses, a series of hierarchical multiple regression analyses was performed to determine whether significant statistical interaction effects exist between gender and the four dimensions of social support on feelings of personal control.

Unlike those in the previous analyses, the finding from the first step in these hierarchical regression analyses failed to provide major insights into the social support process, and as a result, a counterpart to Table I is not presented in this report (a table showing the additive effects of gender and social support on feelings of control can be obtained by writing to the author). However, the second step from the hierarchical procedures indicated that a number of significant interaction effects were present in the data. This information is provided in Table III.

The coefficients in this table represent the unstandardized impact of each dimension of social support on changes in personal control separately for men and women. These estimates were derived from Eq. (2). They were obtained after statistical controls had been established for the effects of age, marital status, education, social desirability, life stress, financial strain, the baseline measures of control, and the additive effects of gender and social support.

In general, the findings provided in Table III suggest that social support tends to increase feelings of control at the follow-up interview among elderly women, but not among older men. More specifically, the results indicate that while high levels of informational support lead to greater changes in feelings of control among elderly women $(b=.038)$, they may actually erode feelings of control among elderly men through time $(b=-.020)$. As shown in Table III, the difference between the coefficients for men and women is significant at the .01 level. Similar effects were observed with both tan- 
Table III. Gender Differences in the Impact of So cial Support on Feelings of Personal Control (T2) ${ }^{a}$

\begin{tabular}{lc}
\multicolumn{2}{c}{$(N=253)$} \\
\hline Effects of informational support for \\
$\quad$ Men \\
$\quad$ Women & -.020 \\
Effects of tangible support for & $.038^{d}$ \\
$\quad$ Men & -.058 \\
$\quad$ Women & $.011^{d}$ \\
Effects of emotional support for & -.008 \\
$\quad$ Men & $.024^{d}$ \\
$\quad$ Women & \\
Effects of support provided to & \\
others for & \\
$\quad$ Men & .001 \\
Women & $.026^{c}$ \\
\hline
\end{tabular}

\footnotetext{
${ }^{a}$ Estimates were derived after controlling for the effects of age, marital status, education, social desirability, the baseline measure of personal control, as well as the additive effects of gender and support. ${ }^{b}$ Unstandardized (metric) coefficient.

${ }^{c}$ Difference between the coefficient for men and women is significant the .05 level.

${ }^{d}$ Difference between the coefficient for men and women is significant at the .01 level.
}

gible and emotional support. Finally, the data in Table III suggest that elderly women are more likely $(b=.026)$ than older men $(b=.001)$ to report that providing support to others increased their own feelings of personal control from $\mathrm{T} 1$ to $\mathrm{T} 2$. Taken as a whole, the findings in Table III tend to provide strong support for the hypothesis that elderly women are more likely than older men to reap greater benefits (in terms of control) from their social support networks when they are confronted by financial strain.

\section{CONCLUSIONS}

In reviewing the literature on gender differences in social support, one is left with the impression that when stressful events arise, elderly women are more liklely than older men to seek and receive assistance from others (espcially nonfamily members). The findings from this study tend to dispel this image. The analyses suggest that as the number of global stressful life events increase, elderly men and women subsequently become equally involved in their social networks. In contrast, gender differences in support emerge only in response to chronic financial strain. This is not to say that gender differences cannot exist in response to any other type of stressor. Instead, the findings suggest that the social support process may be much more com- 
plex than we suspect, and that a fertile area for further work involves the identification of additional stressful circumstances that promote gender differences in social support. By so doing, researchers may be better able to understand how social support buffers the deleterious effects of life stress on health and well-being.

It is important to consider why gender differences emerge when a measure of financial strian is examined but not when an index of global stressful events is used in the analyses. At least part of the explanation may lie in the nature of the events contained in the global stress measure. For example, conjugal bereavement is one event that is likely to be experienced by many older adults. Perhaps bereavement stimulates supportive exchanges among the remaining network members that override or eclipse gender differences that would be likely to emerge under other circumstances. In the general of conjugal bereavement, adult children regardless of their gender would have a clear obligation to assist the surviving aged parent. In effect, this obligation or expectation would suppress gender differences in the receipt or provision of support. This possibility should be kept in mind as researchers test for gender differences in response to other specific types of stressors.

Gender differences in social support may also be especially likely to emerge in response to financial strain because elderly men and women may differ in the extent to which they are responsible for their financial problems and because they may differ in the extent to which they are criticized for their financial difficulties. As discussed earlier, the present cohort of elderly women are less likely than women in more recent generations to have been employed outside the home. Although this may lead elderly women to feel as though they have little control over their financial matters, it may also absolve them of any personal responsibility for the financial difficulties that confront them. In contrast, older men may be much more likely to feel responsible for their financial problems because of the direct control they have exerted over their financial affairs. Perhaps being responsible for the occurrence of an event makes it difficult to seek out or receive assistance from others because contact with others may bring social disapproval and criticism (see Baumgardner \& Aiken, 1987, for a recent discussion of the literature on social disapproval).

Based on existing research, it was hypothesized that elderly women derive special benefits from social support that are not enjoyed by older men. The findings tend to confirm this hypothesis. The data suggest that through time, women are more likely than men to feel as though the support they received and provided increased their feelings of personal control.

There are two reasons why greater confidence may be placed in the linkage between social support and feelings of control. The first pertains to the measurement of personal control. As discussed earlier, the respondents in this study were asked specifically whether the support they received increased 
their feelings of control. This measurement strategy links the two constructs explicitly, thereby forging a stronger bond between two constructs that have previously been related only with global and nonspecific measures. In addition, the analyses provided in this report were based on longitudinal data. Because this kind of data can assess changes in feelings of control through time, we are left with a better feeling for the dynamics involved in the social support process.

The findings involving support provided by study participants to others in their social networks are also potentially important. The findings suggest that as exposure to stress increases, both elderly men and women report providing increased support to others. The data further indicate that older women are especially likely to increase the amount of assistance they provide to others when they are experiencing financial difficulties themselves. As discussed earlier, these results are consistent with the view that individuals who provide support to others frequently benefit themselves from the help-giving role.

The finding that elderly women are more likely than older men to provide support to others in times of financial strain is noteworthy, especially in light of the literature showing that women tend to score below men on measures of personal control across the life course (Rodin et al., 1985). There are two potential explanations for these findings. First, a lifetime of low personal control may make elderly women more sympathetic to the experiences of others, particularly when social network members are confronted with similar problems. The second reason may be related to the differential impact of financial strain on elderly men and women. Since older men have had greater control over financial matters over the life course, the onset of economic difficulties in later life may have a more disruptive effect that diminishes the amount of effort that they can invest in helping others. Because elderly women have experienced a lifetime of lower control over financial matters, the impact of economic problems may be less sudden and less dramatic. Consequently, elderly women may be able to devote more time and effort to helping others.

There are four limitations in this study that should be discussed. The first two pertain to problems with measurement error, the next problem involves the influence of question order effects, while the last limitation involves the need for greater specificity in the measurement of social support.

The effects of random measurement error were not taken into account when the relationships among stress, support, and feelings of control were assessed. As Carmines (1986) demonstrated, such measurement error can lead to biased estimates of the relationships among these constructs.

The problem of measurement error is further compounded when multiplicative terms are used in regression analysis. The work of Bohrnstedt and Marwell (1978) suggests that the reliability of the multiplicative term is fre- 
quently quite low, and that this low reliability further threatens the precision of the parameter estimates. The only major data analytic alternative to the procedure involves subgroup analyses, where the effects of stress are estimated separately for men and women. However, this alternative could not be pursued in this study because of the relatively small number of older men in the sample $(n=88)$.

As Schuman and Presser (1981) observe, the issue of how to order questions in a survey instrument is of great importance because items that appear early in a questionnaire may affect responses to questions that appear later in the interview schedule. Within the context of the present study, questions of financial strain may have influenced responses to subsequent items dealing with personal control. Although it is not possible to determine the extent of this problem, this potentially important limitation must be kept in mind as the findings are reviewed.

Finally, greater specificity may be needed in measuring the types or dimensions of support. This is especially evident with regard to the index of tangible support. The tangible support scale used here encompasses a fairly diverse array of helping behaviors, including assistance with housework chores as well as help with yardwork. A careful examination of these specific supportive acts reveals that some are more likely to be provided by elderly women (e.g., housework), while other types of assistance are more likely to be given by elderly men (e.g., yardwork). In the future, it may be helpful to disaggregate this measure into gender-specific subscales of tangible aid. Subsequent analysis with these subscales may help specify gender differences in the relationships among stress, support, and feelings of personal control more clearly.

In spite of these limitations, we hope this research will encourage further study of the determinants of social support among older adults. If we carefully examine why older adults give and receive support, we may be in a better position to find out why social support has a beneficial effect, and why it may play an important role in the maintenance restoration of health and psychological well-being.

\section{REFERENCES}

Alloway, R., \& Bebbington, P. The buffer theory of social support-A review of the literature. Psychological Medicine, 1987, 17, 91-108.

Antonucci, T. Social support: theoretical advances, recent findings and pressing issues. In I. Sarason \& B. Sarason (Eds.), Social support: Theory, research, and applications. The Hague, The Netherlands: Martinus Nijhoff, 1985. (a)

Antonucci, T. Personality characteristics, social support, and social behavior. In R. Binstock \& E. Shanas (Eds.), Handbook of aging and the social sciences. New York: Van Nostrand Reinhold, 1985. (b) 
Barrera, M., Sandler, I., \& Ramsay, T. Preliminary development of a scale of social support: Studies on college students. American Journal of Community Psychology, 1981, 9, 435-447.

Baumgardner, A., \& Arkin, R. Coping with the prospect of disapproval: Strategies and sequelae. In C. Snyder \& C. Ford (Eds.), Coping with negative events: Clinical and social psychological perspectives. New York: Plenum, 1987.

Bengtson, V., Reedy, M., \& Gordon, C. Aging and self-conceptions, personality processes and social contexts. In J. Birren \& K. Warner Schaie (Eds.), Handbook of psychology and aging. New York: Van Nostrand Reinhold, 1985.

Block, J. Another look at sex differentiation in the socialization of mothers and fathers. In J. Sherman \& F. Denmark (Eds.), Psychology of women: Future directions of research. New York: Psychological Dimensions, 1979.

Bohrnstedt, G., \& Marwell, G. The reliability of products of two random numbers. In K. Schuessler (Ed.), Sociological methodology. San Francisco: Jossey-Bass, 1978.

Bradburn, N., \& Sudman, S. Reinterpreting the Marlowe-Crowne scale. In N. Bradburn \& S. Sudman (Eds.), Improving interview method and questionnaire design. San Francisco: Jossey-Bass, 1979.

Brown, G., \& Harris, T. Social origins of depression. New York: Free Press, 1978.

Burkhauser, R., Holden, K., \& Feaster, D. Incidence, timing, and events associated with poverty: A dynamic view of poverty and retirement. Journal of Gerontology, 1988, 43, 546-552.

Butler, T., Giordano, S., \& Neren, S. Gender and sex-role attributes as predictors of utilization of natural support systems during personal stress events. Sex Roles, 1985, 13, 515-524.

Campbell, A. A sense of well-being in America. New York: McGraw-Hill, 1980.

Caplan, G. Mastery of stress: Psychosocial aspects. American Journal of Psychiatry, 1981, 138, 413-420.

Carmines, E. The analysis of covariance structure models. In W. Berry \& M. Lewis-Beck (Eds.), New tools for social scientists. Beverly Hills, CA: Sage, 1986.

Carr, L., \& Krause, N. Social status, psychiatric symptomatology, and response bias. Journal of Health and Social Behavior, 1978, 22, 117-129.

Crowne, D., \& Marlowe, D. The approval motive: Studies in evaluative dependence. New York: Wiley, 1964.

DeFares, P., Brandes, M., Nass, C., \& van der Ploeg, J. Coping styles, social support, and sex-differences. In I. Sarason, \& B. Sarason (Eds.), Social support: Theory, research, and applications. The Hague, The Netherlands: Martinus Nijhoff, 1985.

Dunkel-Schetter, C., Folkman, S., \& Lazarus, R. Correlates of social support receipt. Journal of Personality and Social Psychology, 1987, 53, 71-80.

Fasteau, M. The male machine. New York: McGraw-Hill, 1974.

Henderson, S., Bryne, D., \& Duncan-Jones, P. Neurosis and the social environment. New York: Academic Press, 1981.

Holden, K. Poverty and living arrangements among older women: Are changes in economic well-being underestimates? Journal of Gerontology, 1988, 43, S22-S27.

Hyman, H. Of time and widowhood: Nationwise studies of enduring effects. Durham, NC: Duke Press Policy Studies, 1983.

Kessler, R., McLeod, J., \& Wethington, E. The costs of caring: A perspective on the relationship between sex and psychological distress. In I. Sarason \& B. Sarason (Eds.), Social support: Theory, research and applications. The Hague, The Netherlands: Martinus Nijhoff, 1985.

Kish, L. Survey sampling. New York: Wiley, 1965.

Krause, N. Social support, stress, and well-being among older adults. Journal of Gerontology, $1986,41,512-519$.

Krause, N. Chronic strain, locus of control, and distress in older adults. Psychology and Ag ing, 1987, 2, 375-382.

Lee, G. Kinship and social support of the elderly: The case of the United States. Aging and Society, $1985,5,19-38$.

Levine, M., \& Perkins, D. Principles of community psychology: Perspectives and applications. New York: Oxford University Press, 1987. 
Morgan, L. Continuity and change in labor force activity among recently widowed women. The Gerontologist, 1984, 24, 530-535.

Morgan, L. The financial experience of widowed women: Evidence from the LRHS. The Gerontologist, 1986, 26, 663-668.

Pearlin, L., Menaghan, E., Lieberman, M., \& Mullan, J. The stress process. Journal of Health and Social behavior, 1981, 22, 337-356.

Reissman, F. The helper principle. Social Work, 1965, 10, 27-32.

Rodin, J., Timko, C., \& Harris, S. The construct of control: Biological and psychological correlates. In M. P. Lawton \& G. Maddox (Eds.), Annual review of gerontology and geriatrics, volume 5. New York: Springer, 1985.

Rotter, J. Generalized expectancies for internal versus external control of reinforcement. Psychological Monographs: General and Applied, 1966, 80(1, Whole No. 609), 1-28.

Schuman, H., \& Presser, S. Questions and answers in attitude surveys. New York: Academic Press, 1981.

Stolzenberg, R. The measurement and decomposition of causal effects in nonlinear and nonadditive models. In K. Schuessler (Ed.), Sociological Methodology. San Francisco: JosseyBass, 1980.

Thoits, P. Dimensions of life stress that influence psychological distress: An evaluation and synthesis of the literature. In H. Kaplan (Ed.), Psychological stress: Trends in theory and research. New York: Academic Press, 1983.

Varghese, R., \& Medinger, F. Fatalism in response to stress among the minority aged. In D. Gelfand \& A. Kutzik (Eds.), Ethnicity and aging: Theory, research, and policy. New York: Springer, 1979.

Verhoff, J., Douvan, E., \& Kulka, R. The inner American. New York: Basic Books, 1981.

Wortman, C., \& Dunkel-Schetter, C. Conceptual and methodological issues in the study of social support. In A. Baum \& J. E. Singer (Eds.), Handbook of psychology and health, Volume 5: Stress. Hillsdale, NJ: Lawrence Erlbaum, 1987. 